Ngày nay, việc sử dụng điện thoại thông minh tại Việt Nam càng ngày càng phổ biến. Dũ liệu thống kê cho thây năm 2020 Việt Nam có 38,44 triệu người sử dụng điện thoại thông minh và tiếp tục tăng trưởng mạnh. Khảo sát ban đâu về nhu cầu sử dụng app hỗ trợ CBĐT của chúng tôi cũng cho thây $85,3 \%$ bệnh nhân và người nhà có sử dụng điện thoại thông minh; và $88,4 \%$ sẵn sàng sử dụng app hỗ trợ CBĐT trên điện thoại, trong đó 70,4\% mong muốn được sử dụng app miễn phí [4]. Đây có thể cách tiếp cận mới, thân thiện giúp cải thiện hiểu biết và tăng cường mức độ chủ động tham gia của bệnh nhân/người nhà từ đó nâng cao chất lượng NSĐT.

Nghiên cứu mới chỉ khảo sát mức đô làm sạch đại tràng, cần có thêm một số nghiên cứu đánh giá thêm về tính khả thi, mức độ hài lòng của bệnh nhân, nhân viên y tế và chi phí y tế khi so sánh với phương pháp truyền thống.

\section{KẾT LUẬN}

Nghiên cứu can thiệp lâm sàng, mù đơn có nhóm chứng trên 432 người bệnh về quá trình chuẩn bị làm sạch đại tràng chúng tôi có kết luận sau: Tỷ lệ làm sạch đại tràng ở nhóm sử dụng app cao hơn nhóm được hướng dẫn theo thường quy. Đây là app hỗ trợ CBĐT đầu tiên tại Việt Nam trong lĩnh vực nội soi tiêu hóa cho thấy tính khả thi trong quá trình triển khai và sự cải thiện mức độ làm sạch vì thế có thể cân nhắc sử dụng rộng rãi ở nhiểu đơn vị y tế.

\section{TÀI LIÊU THAM KHẢO}

1. World Health Organization, Global cancer observatory in Vietnam 2018. 2019, International Agency for research on cancer.

2. Sharara, A.I., et al., A Customized Mobile Application in Colonoscopy Preparation: A Randomized Controlled Trial. Clinical and Translational Gastroenterology, 2017. 8(1): p. e211.

3. Desai, M., et al., Use of smartphone applications to improve quality of bowel preparation for colonoscopy: a systematic review and metaanalysis. Endoscopy International Open, 2019. 07(02): p. E216-E224.

4. Đào Việt Hằng, Trân Thị Thanh Lịch, and Đào Viết Quân, Đánh giá mức độ hài lòng và khảo sát nhu cầu về ứng dụng hướng dẫn chuẩn bị nội soi đai tràng trên điện thoai thông minh $Y$ học thực hành, 2020. 1124(Số 1/2020): p. 10-13.

5. Đào Viết Quân, Đố Thị Việt Phương, and Hoàng Anh Tú, Đánh giá hiêu quả làm sach của Fleet phosphor soda so với Fortrans trên người bênh có chì đinh nôi soi đai tràng tai Bênh viên Đai học Y Hà Nối. 2017, Đề tài cơ sở Bệnh viện Đại hớ Y Hà Nôi.

6. Lai, E.J., et al., The Boston bowel preparation scale: a valid and reliable instrument for colonoscopy-oriented research. Gastrointest Endosc, 2009. 69(3 Pt 2): p. 620-5.

7. Hassan, C., et al., Bowel preparation for colonoscopy: European Society of Gastrointestinal Endoscopy (ESGE) Guideline - Update 2019. Endoscopy, 2019. 51(08): p. 775-794.

8. Chan, W.K., et al., Appointment waiting times and education level influence the quality of bowel preparation in adult patients undergoing colonoscopy. BMC Gastroenterol, 2011. 11: p. 86.

\title{
MỐI TƯƠ'NG QUAN GIỮA CÁC THÔNG SỐ BIẾN DANG THẤT TRÁI ĐO TRÊN SIÊU ÂM ĐÁNH DẤU MÔ 3D VớI PHÂN SUẤT TỐNG MÁU THẤT TRÁI Ở BỆNH NHÂN SUY TIM MẠN TÍNH
}

Nguyễn Thị Kiều Ly', Đỗ Văn Chiến'1, Phạm Thái Giang ${ }^{1}$, Phạm Nguyên Sơn ${ }^{1}$.

\section{TÓM TẮT}

Mục tiêu: Đánh giá mối tương quan giữa các thông số biến dạng và vận động xoắn thất trái đo trên siêu âm đánh dẩu mô 3D với phân suất tống máu thất trái ở bệnh nhân suy tim mạn tính. Đối tượng và phương pháp: Nghiên cứu được thực hiện trên 110 bệnh nhân suy tim mạn tính được điều trị nội trú tại khoa Nội Tim mạch, Bệnh viện TWQĐ 108 từ 01/2018

*Bênh viên Trung Ương Quân độ 108.

Chịu trách nhiệm chính: Nguyễn Thị Kiều Ly

Email: nklyrose@gmail.com

Ngày nhận bài: 8.4.2021

Ngày phản biên khoa hoc: 27.5.2021

Ngày duyệt bài: 8.6 .2021 đến 10/2020. Kết quả: Có mối tương quan chặt chẽ giữa các thông số biến dạng với phân suất tống máu thất trái ( $\mathrm{GLS} r=0,67$; GRS $r=0,80$, GCS $r=0,80$; GAS $r=0,83$ với $p<0,001)$. Tương quan chăht chẽ hơn được thây trong nhóm suy tim phân suất tống máu giảm so với nhóm suy tim phân suất tống máu bảo tồn (GLS $r=0,62$ so với $r=0,30$, GRS $r=0,74$ so với $r=0,55$; GCS $r=0,75$ so với $r=0,63 ;$ GAS $r=0,77$ so với $r=0,67)$. Các thông số biến dạng thất trái tương quan với phân suất tống máu thất trái đo trên 3D manh hơn với phân suất tống máu đo trên 2D (GLS r=0,76 so với $r=0,67$; GRS $r=0,93$ so với $r=0,80$; GCS $r=0,92$ so với $r=0,80$; GAS $r=0,94$ so với $r=0,83)$. Kết luận: Các thông số biến dang thất trái có tương quan rất chặt với $E F$, biến dạng diện tích có tương quan mạnh nhất. Mối tương quan chặt hơn được thấy ở nhóm suy tim phân suất 
tống máu giảm. Các thông số biến dạng có tương quan với EF đo trên siêu âm 3D mạnh hơn so với EF đo trên siêu âm 2D.

Tư khóa: siêu âm 3D, biến dạng thất trái, suy tim.

\section{SUMMARY}

\section{ASSOCIATION BETWEEN LEFT VENTRICULAR MYOCARDIAL DEFORMATION ASSESSED USING THREE DIMENSIONAL SPECKLE TRACKING ECHOCARDIOGARPHY AND EJECTION FRACTION IN HEART FAILURE}

Objective: to evaluate the correlation between deformation parameters on 3D speckle tracking echocardiography (STE) with left ventricular ejection fraction (EF) in patients with chronic heart failure. Subjects and methods: a prospective, cross-sectional study with was performed on 110 chronic heart failure patients treated at Department of Cardiology, 108 Central Hospital from january 2018 to october 2020. Results: There was a strong positive correlation between deformation parameters and left ventricular ejection fraction $E F(r=0.67$ for $G L S ; r=0.80$ for GRS, $r=0.80$ for GCS; $r=0.83$ for GAS with $p<0,001)$. The strong correlation was more pronounced in the heart failure group with reduce EF compared to that of preserved $E F(G L S r=0.62$ vs $r=0,30$, GRS $r=0.74$ vs $r=0.55 ;$ GCS $r=0.75$ vs $r=0.63$; GAS $r=0.77$ vs $r=0.67$ ). The parameters of left ventricular deformatoin are positively correlated with EF measured on 3D stronger than with $\mathrm{EF}$ measured on 2D (GLS $r=0.76$ vs $r=0.67 ;$ GRS $r=0.93$ vs $r=0.80$; GCS $r=0.92$ vS $r=0.80 ;$ GAS $r=0.94$ vs $r=0.83$ ). Conclusion: Left ventricular deformation parameters are closely correlated with $\mathrm{EF}$, GAS has the strongest correlation. The correlation is stronger in the reduced EF group compared to preserved EF and better by 3D echocardiography compared to 2D.

Keywords: 3D echocardiography, left ventricular deformation, heart failure.

\section{I. ĐĂT VẤN ĐỀ}

Trong thực hành lâm sàng phân suất tống máu thất trái $E F$ là thông số quan trong trong đánh giá chức năng thất trái, đánh giá nguy cơ tim mạch, là yếu tố tiên lượng quan trọng [1]. EF vẫn là thông số thông dụng nhất, được sử dụng trong các khuyến cáo như các tiêu chuẩn để đưa ra các quyết định lâm sàng. Tuy nhiên, việc đánh giá $\mathrm{EF}$ có nhiều hạn chế. Xác định $\mathrm{EF}$ dựa vào sự giả định hình học thất trái, phụ thuộc vào chất lượng hình ảnh, sai số lớn giữa các lần đo và những người đo khác nhau [2]. Gần đây với sự phát triển của siêu âm đánh dấu mô cho phép chúng ta đánh giá được những biến đổi cấu trúc, chức năng tim thông qua các thông số biến dạng (hay sức căng) cơ tim. Trong đó siêu âm tim đánh dấu mô 3D là phương pháp mới, đánh giá được các thông số biến dạng trong không gian 3 chiều, khắc phục được các nhược điểm của siêu âm tim đánh dấu mô $2 \mathrm{D}$ [3]. Trền thế giới cũng như ở Việt Nam chưa có nhiều nghiên cứu về vấn đề này. Vì vậy, chúng tôi thực hiện nghiên cứu này với mục tiêu: Tìm hiêu mối tương quan giữa các thông số biên dạng thất trái với phân suất tống máu thất trái.

\section{II. ĐỐl TƯỢNG VÀ PHƯƠNG PHÁP NGHIÊN CỨU \\ Đối tượng và phương pháp: Nghiên cứu} được tiến hành trên 110 bệnh nhân suy tim mạn tính được điều trị nội trú tại Bệnh viện Trung Ương Quân Đội 108 trong thời gian từ 01/2018 đến 12/2020.

Tiêu chuẩn lựa chọn: Bệnh nhân được chẩn đoán suy tim theo khuyến cáo hội Tim mạch Châu Âu năm 2016 [4] và đồng ý tham gia nghiên cứu.

Tiêu chuẩn loại trừ: Bệnh nhân có rung nhĩ, cuồng nhĩ hoặc nhịp chậm < 50 lần/ phút, hoặc nhịp nhanh > 100 lần/ phút. Bệnh van tim. Tim bẩm sinh. Bệnh nhân có bệnh cấp tính không làm siêu âm được. Hình ảnh siêu âm không rõ nét và không phẩn tích được.

Đánh giá các thông số biến dạng (sức căng) thất trái bằng siêu âm tim: Tất cả các bệnh nhân đều được thăm khám lâm sàng và được lấy phiếu chấp thuận vào nghiên cứu. Siêu âm tim được thực hiện trên máy siêu âm Philip EQI 7C với đầu do ma trận X5 (Philips Healthcare, Hà Lan): ghi hình động các mặt cắt cơ bản có mặc điện tim kèm theo và hình ảnh động 3D toàn bộ thất trái (Fullvolume toàn bộ thất trái) trên 4 nhịp tim liên tiếp. Sau đó chuyển sang trạm phân tích có tích hợp phần mềm TOMTEC Arena (TOMTEC- CHLB Đức). Phân tích các thông số cơ bản và các thông số biến dạng.

Một số chỉ số đo được trong nghiên cứu như sau: đo các thông số siêu âm cơ bản về kích thước theo khuyến cáo của Hội siêu âm tim Hoa Kỳ, chỉ số EF được tính theo phương pháp Simpson. Các chỉ số biến dạng thất trái được tính toán tự động bằng phần mềm TOMTEC (Hà Lan), gồm các thông số:

GLS (global longitudinal strain): Sức căng trục dọc thất trái. Do khi co bóp thất trái ngắn lại theo trục dọc nên GLS có giá trị âm -, đơn vị là \%. GRS (global radial strain): Sức căng theo chiều bán kính thất trái. Khi co bóp thất trái sẽ dây lên theo chiều bán kính nên GRS có giá trị dương, đơn vị là \%. GCS (global circumferential strain): Sức căng theo chiêu chu vi thất trái. Khi co bóp thất trái co nhỏ theo chiều chu vi nên GCS có giá trị âm -, đơn vị là \%. GAS (Global area 
strain): Sức căng diện tích thất trái, là sự biến đổi diện tích bề mặt nội mạc thất trái khi co bóp, nó là tổng hợp sự biến đổi theo chiều chu vi và theo trục dọc nên GAS có giá trị âm -, đơn vị là \%.

Xử lý số liệu: Bằng phần mềm SPSS 22.0. Các biến định lượng được biểu diễn dưới dạng số $\mathrm{TB} \pm$ Độ lệch chuẩn, biến định tính được biểu diễn dạng phần trăm (\%). Tìm mối tương quan bằng thuật toán Pearson. Giá trị $p<0,05$ được coi là có ý nghĩa thống kê.

\section{KẾT QUẢ NGHIÊN CỨU}

Bảng 1. Đặc điểm tuổi, giới và nhân trắc của nhóm nghiên cứu

Thông số $(n=110)$

\begin{tabular}{|c|c|}
\hline Tuổi trung bình (năm) & $65,82 \pm 11,77$ \\
\hline Giới nam, $\mathrm{n}(\%)$ & $73(66,36 \%)$ \\
\hline Giới nữ, $\mathrm{n}(\%)$ & $37(33,64 \%)$ \\
\hline Chiều cao $(\mathrm{cm})$ & $58,29 \pm 10,67$ \\
\hline Cân nă̆ng $(\mathrm{kg})$ & $1,60 \pm 0,07$ \\
\hline BMI $\left(\mathrm{kg} / \mathrm{m}^{2}\right)$ & $22,7 \pm 3,53$ \\
\hline BSA (m²) & $1,67 \pm 0,17$ \\
\hline Huyết áp tâm thu & $128,72 \pm 20,90$ \\
\hline Huyết áp tâm trương & $78,44 \pm 12,90$ \\
\hline Tần số tim & $85,64 \pm 14,94$ \\
\hline
\end{tabular}

Tuối trung bình của nhóm bệnh nhân trong nghiên cứu là $65,82 \pm 11,77$, nam giới chiếm đa số (66,36\%). Các chỉ số BMI, huyết áp tâm thu, huyết áp tâm trương, nhịp tim đều trong giới hạn bình thường.

Bảng 2: Mối tương quan giữa các thông số biến dạng thất trái với EF ở nhóm suy tim

\begin{tabular}{|c|c|c|c|}
\hline Chỉ số (n=110) & $\mathbf{r}$ & $\mathbf{p}$ & Phương trình hồi quy \\
\hline GLS & $-0,67$ & $<0,001$ & GLS1 $=-3,94-0,177 * \mathrm{EFS}$ \\
\hline GRS & 0,80 & $<0,001$ & GRS1 $3,47+0,46 * \mathrm{EFs}$ \\
\hline GCS & $-0,80$ & $<0,001$ & GRS2 $=-0,33-0,378 * \mathrm{EFs}$ \\
\hline GAS & $-0,83$ & $<0,001$ & $\mathrm{GAS} 1=-2,27-0,413 * \mathrm{EFs}$ \\
\hline
\end{tabular}

Có mối tương quan thuận chặt giữa biến dạng thất trái theo chiều bán kính (GRS) với phân suất tống máu thất trái(EF), tương quan nghịch chặt giữa biến dạng theo các chiều dọc, chu vi và diện tích với $\mathrm{EF}$. Tương quan mạnh nhất là được thấy ở biến dạng theo diện tích, tiếp đến là biến dạng chiều bán kính và chu vi, yểu nhất là biến dạng theo trục dọc.

Bảng 3. Môi tương quan giữa các thông số biến dạng thất trái với EF ở các nhóm suy tim

\begin{tabular}{|c|c|c|c|c|}
\hline \multirow{2}{*}{ Thông số } & EF $<\mathbf{5 0 \%} \mathbf{( n = 7 0 )}$ & \multicolumn{2}{c|}{ EF $\mathbf{2 5 0} \% \mathbf{n}=\mathbf{3 0})$} \\
\cline { 2 - 5 } & $\mathbf{r}$ & $\mathbf{p}$ & $\mathbf{r}$ & $\mathbf{p}$ \\
\hline GLS & $-0,62$ & $<0,001$ & $-0,30$ & $<0,001$ \\
\hline GRS & 0,74 & $<0,001$ & 0,55 & $<0,001$ \\
\hline GCS & $-0,75$ & $<0,001$ & $-0,63$ & $<0,001$ \\
\hline GAS & $-0,77$ & $<0,001$ & $-0,67$ & $<0,001$ \\
\hline
\end{tabular}

Các thông số biến dạng thất trái theo các chiều (dọc, bán kính, chu vi, diện tích) có tương quan chặt chẽ hơn với phân suất tống máu thất trái ở nhóm suy tim phân suất tống máu giảm so với nhóm suy tim có phân suất tống máu bảo tồn.

Bảng 4: Mối tương quan giữa các thông số biến dạng thất trái đo trên siêu âm 3D với EF đo trên siêu âm 2D và 3D

\begin{tabular}{|c|c|c|c|c|}
\hline \multirow{2}{*}{ Thông số } & \multicolumn{2}{|c|}{ EF 2D } & \multicolumn{2}{c|}{ EF 3D } \\
\cline { 2 - 5 } & $\mathbf{r}$ & $\mathbf{P}$ & $\mathbf{r}$ & $\mathbf{P}$ \\
\hline GLS & $-0,67$ & $<0,001$ & $-0,76$ & $<0,001$ \\
\hline GRS & 0,80 & $<0,001$ & 0,93 & $<0,001$ \\
\hline GCS & $-0,80$ & $<0,001$ & $-0,92$ & $<0,001$ \\
\hline GAS & $-0,83$ & $<0,001$ & $-0,94$ & $<0,001$ \\
\hline
\end{tabular}

Biến dạng thất trái theo các hướng (dọc, bán kính, chu vi và diện tích) có tương quan với phân suất tống máu đo trên siêu âm 3D chặt chẽ hơn phân suất tống máu đo trên siêu âm 2D.

\section{BÀN LUẬN}

Nhóm nghiên cứu có tuổi trung bình là 65,82 $\pm 11,77$, trong đó nam giới chiếm đa số (66,36\%). Đây là nhóm tuổi thường gặp trong suy tim. Figueroa (2006) thấy ở Mỹ số bệnh nhân suy tim phải nhập viện có tuổi trên 65 chiếm tới 80\% [5].

Chúng tôi thấy có mối tương quan rất chặt chẽ giữa các thông số biến dạng thất trái với phân suất tống máu thất trái. Kleijn và cộng sự [6]. Trong đó tương quan mạnh nhất là biến dạng diện tích GAS $(r=0,83)$, rồi đến GRS, GCS và yếu nhất là biến dạng trục dọc $\mathrm{GLS}(r=0,67)$. Luis và cộng sự cũng cho kết quả các thông số biến dạng thất trái có tương quan rất chă̆t chẽ với $E F$, tương quan mạnh nhất được thây giữa $\mathrm{GAS}$ và $\mathrm{EF}$ $(r=0,89)$, yếu nhất là GLS với $E F(r=0,76)[7]$. Có mối tương quan mạnh như vậy là do cơ tim có 3 
lớp chính là lớp nội mạc chủ yếu các sợi chạy theo hướng dọc, lớp giữa chủ yếu là các sợi cơ chạy theo hướng vòng chu vi song song với mặt phẳng vòng van và lớp ngoại mạc có các sợi cơ chạy theo hướng dọc. Lớp cơ ở giữa vượt trội lớp cơ dọc với tỷ lệ $10: 1$, tỷ lệ các sợi cơ chạy theo hướng chu vi nhiều ở phần nền và giảm dần về phía mỏm. Do đó lớp cơ theo hướng chu vi đóng vai trò lớn hơn và quan trọng hơn so với lớp cơ dọc trong chức năng thất trái [8].

Nhiều nghiên cứu trước đã chứng minh vai trò của GCS quan trọng hơn GLS trong duy trì chức năng thất trái [9]. GAS là biến dạng diện tích phản ánh sự biến dạng của bề mặt nội tâm mạc, trong quá trình co lại sẽ giảm kích thước diện tích thông qua sự rút ngắn theo chiều dọc và theo chu vi, và sự dày lên theo hướng tâm nó được xác định bằng véc tơ biến dạng theo hướng dọc GLS và chu vi GCS ở cuối thì tâm thu so với diên tích ban đầu của nó ở cuối thì tâm trương. Nhiều tác giả đã chỉ ra GAS là thông số rất nhạy trong phát hiện những biến đổi sớm chức năng thất trái. Trong nghiên cứu của mình Wen đã chỉ ra GLS, GRS giảm ở nhóm suy tim giai đoạn $A$ nhưng không có sự khác biệt, chỉ riêng GAS giảm ở nhóm suy tim giai đoạn $A$ so với nhóm chứng với sự khác biệt có ý nghĩa thống kê. Nếu tổng hợp cả sức căng trục dọc và chu vi là $50 \%$, thì tỉ lệ biến dạng theo chiêu chu vi đạt tới $75 \%$. Do đó, một thay đổi nhỏ về chức năng thất trái có thể được phân biệt bởi GAS so với 1 giá trị sức căng GLS hoặc GCS. Có thể gợi ý rằng GAS vượt qua những thông số truyền thống trong việc phát hiện những biến đổi sớm chức năng tâm thu thất trái.

Nghiên cứu của chúng tôi cũng chỉ ra tương quan giữa các thông số biến dạng thất trái với phân suất tống máu thất trái đo trên $3 \mathrm{D}$ mạnh hơn với phân suất tống máu đo trên $2 \mathrm{D}$. Nhiều nghiên cứu chỉ ra rằng siêu âm $3 \mathrm{D}$ khắc phục được những nhược điểm của siêu âm $2 \mathrm{D}$, cho phép đánh giá chính xác thể tích và phân suất tống máu thất trái, không phải sử dụng giả định hình học như trong siêu âm 2D. Nghiên cứu của Luis và cộng sự cũng thấy tương quan của các thông số biến dạng thất trái với phân suất tống máu đo trên 3D mạnh hơn với phân suất tống máu thất trái đo trên 2D [7]. Xiu Xiu Luo và cộng sự cũng thấy tương quan giữa các thông số biến dạng với phân suất tống máu đo trên $3 \mathrm{D}$ là rất chặt chẽ với GAS $(r=0,98, p<0,001)$, GCS $(r=0,92, p<0,001), G L S(r=0,72, p<0,001)$

Khi phân ra các nhóm suy tim, chúng tôi thây mối tương quan giữa các thông số biến dạng thất trái với phân suất tống máu thất trái ở nhóm suy tim phân suất tống máu giảm chặt chẽ hơn nhóm suy tim phân suất tống máu bảo tồn. Kết luận này càng khẳng định hơn đối với những trường hợp suy tim phân suất tống máu bảo tồn, phân suất tống máu không có giá trị trong tiên lượng, dự đoán rối loạn chức năng thất trái hay dự báo các kết cục lâm sàng của nhóm bệnh. Khi đó ở những trường hợp này chúng ta nên sử dụng các thông số biến dạng thất trái.

\section{KẾT LUÂ̂N}

Các thông số biến dạng thất trái có tương quan chặt chẽ với phân suất tống máu thất trái trên siêu âm $2 \mathrm{D}$ và $3 \mathrm{D}$, trong đó tương quan mạnh mẽ hơn được thấy với phân suất tống máu đo trên 3D. Trong các thông số biến dạng thì biến dạng diện tích có tương quan mạnh nhất với phẩn suất tống máu, sau đó đến biến dạng chu vi và bán kính, yếu nhất là biến dạng trục dọc. Tương quan giữa các thông số biến dạng thất trái với phân suất tống máu thất trái được thấy chặt chẽ hơn ở nhóm suy tim phân suất tống máu giảm so với nhóm suy tim phân suất tống máu bảo tồn.

\section{TÀI LIÊU THAM KHẢO}

1. Solomon, S., et al., Candesartan in Heart Failure Reduction in Mortality I. Influence of ejection fraction on cardiovascular outcomes in a broad spectrum of heart failure patients. Circulation, 2005. 112: p. 3738-3744.

2. Cikes, M. and S.D. Solomon, Beyond ejection fraction: an integrative approach for assessment of cardiac structure and function in heart failure. European heart journal, 2016. 37(21): p. 16421650.

3. Muraru, D., et al., Three-dimensional speckletracking echocardiography: benefits and limitations of integrating myocardial mechanics with threedimensional imaging. Cardiovascular diagnosis and therapy, 2018. 8(1): p. 101.

4. Ponikowski, P., et al., 2016 ESC Guidelines for the diagnosis and treatment of acute and chronic heart failure: The Task Force for the diagnosis and treatment of acute and chronic heart failure of the European Society of Cardiology (ESC)Developed with the special contribution of the Heart Failure Association (HFA) of the ESC. European Heart Journal, 2016. 37(27): p. 2129-2200.

5. Figueroa, M.S. and J.I. Peters, Congestive heart failure: diagnosis, pathophysiology, therapy, and implications for respiratory care. Respiratory care, 2006. 51(4): p. 403-412.

6. Kleijn, S.A., et al., Comparison between threedimensional speckle-tracking echocardiography and cardiac magnetic resonance imaging for quantification of left ventricular volumes and function. European Heart Journal-Cardiovascular Imaging, 2012. 13(10): p. 834-839.

7. Luis, S.A., et al., Use of three-dimensional 
speckle-tracking echocardiography for quantitative assessment of global left ventricular function: a comparative study to three-dimensional echocardiography. J Am Soc Echocardiogr, 2014. 27(3): p. 285-91.

8. Streeter Jr, D.D., et al., Fiber orientation in the canine left ventricle during diastole and systole.
Circulation research, 1969. 24(3): p. 339-347.

9. Matsumoto, $K_{\text {., }}$ et al., Contractile reserve assessed by three-dimensional global circumferential strain as a predictor of cardiovascular events in patients with idiopathic dilated cardiomyopathy. Journal of the American Society of Echocardiography, 2012. 25(12): p. 1299-1308.

\section{ĐÁNH GIÁ KẾT QUẢ Đİ̂̀U TRỊ SỎI THÂ̂N SAN HÔ BẰNG PHƯƠNG PHÁP TÁN SỎI QUA DA ĐƯờNG HẦM NHỎ TẠI BỆNH VIỆN ĐA KHOA TİNH HẢI DƯO'NG NĂM 2020}

\section{TÓM TẮT}

Mục tiêu: Đánh giá kết điều trị sỏi thân san hô bằng phương pháp tán sỏi thận qua da đường hầm nhỏ tai Bênh viên Đa khoa tỉnh Hải Dương năm 2020. Phương pháp: Nghiên cứu mô tả, cắt ngang 52 bệnh nhân sỏi thân san hô được điều trị bằng tán sỏi nôi soi qua da đường hầm nhỏ tại bệnh viện đa khoa tỉnh Hải Dương. Kết quả: Tuổi trung bình: $54,9 \pm 11,9$ tuổi; Kích thước sỏi trung bình trên cắt lớp vi tính là $28,1 \pm$ $5,6 \mathrm{~mm}$; Số lượng sỏi: $69,2 \%$ có 1 viên, $7,7 \%$ có 2 viên và $23,1 \%$ có từ 3 viên trở lên; Phân loại sỏi: Sỏi san hô toàn phần $2 / 52$ bệnh nhân, sỏi san hô bán phần 50/52 bệnh nhân (chiếm 96,2\%); Số lần chọc dò: $84,6 \% 1$ lần chọc, $11,5 \% 2$ lấn chọc và 3,8\% 3 lần chọc dò; Số đường hâm: 1 đường hầm 37/52 bệnh nhân (chiếm $71,2 \%$ ), 2 đường hầm 15/52 bệnh nhân (chiếm 28,8\%); Thời gian chọc dò: 13,31 $\pm 6,14$ phút; Tỷ lệ biến chứng sau phẫu thuật là 13/52 bệnh nhân (chiểm 25,0\%); Tỷ lệ sạch sỏi sau 3 ngày là: $67,3 \%$, sau 1 tháng là $80,8 \%$; Kết quả chung sau phấu thuât: Tốt $67,3 \%$, trung bình $30,8 \%$, xấu 1,9\%. Kết luận: Điều trị sỏi thận san hô bằng phương pháp tán sỏi nồi soi qua da tại bệnh viện Đa khoa tỉnh Hải Dương là phương pháp an toàn, hiệu quả với tỷ lệ sạch sỏi cao và tai biến biến chứng thấp.

\section{SUMMARY}

EVALUATE THE RESULT OF TREATMENT OF CORAL KIDNEY STONE BY MINI PERCUTANEOUS NEPHROLITHOTOMY TREATMENT AT

HAI DUONG GENERAL HOSPITAL IN 2020

Objective: To evaluate the result of treatment of coral kidney stone by mini percutaneous nephrolithotomy at Hai Duong General Hospital in 2020. Methods: Descriptive cross - sectional study of 52 patients with coral kidney stone undergone treatment treated with mini percutaneous

*Trường cao đẳng y tế Hà Nội

**BV đa khoa tỉnh Hải Dương

Chịu trách nhiệm chính: Nguyễn Minh An

Email: Dr minhan413@yahoo.com

Ngày nhận bài: 9.4.2021

Ngày phản biên khoa hoc: 27.5.2021

Ngày duyệt bài: 9.6.2021

\section{Nguyễn Minh An*, Đỗ Hải Hùng**}

nephrolithotomy at Hai Duong General Hospital in 2020. Results: The mean age was $54.9 \pm 11.9$ years old; The mean stone size on computed tomography was $28.1 \pm 5.6 \mathrm{~mm}$; Number of stones: 1 stone was $69.2 \%, 2$ stones was $7.7 \%$ and 3 or more stones was $23.1 \%$; Classification of stones: coral stones with $2 / 52$ patients, partial coral stones with $50 / 52$ patients $(96.2 \%)$; Number of punctures: 1 time was $84.6 \%, 2$ times was $11.5 \%$ and 3 times was $3.8 \%$; Number of tunnels: 1 tunnel with 37/52 patients (71.2\%), 2 tunnels with $15 / 52$ patients $(28.8 \%)$; Probe time: $13.31 \pm 6.14$ minutes; The rate of complications after surgery was $25 \%$ with $13 / 52$ patients; The rate of stone removal after 3 days was: $67.3 \%$, after 1 month was $80.8 \%$; Overall outcome after surgery: Good was $67.3 \%$, average was $30.8 \%$, bad was $1.9 \%$. Conclusion: Treatment of coral kidney stones by mini percutaneous nephrolithotomy at Hai Duong General Hospital is safe and effective with high stone clearance rate and less complication.

\section{I. ĐĂT VẤN ĐỀ}

Sỏi tiết niệu là bệnh lý thường gặp ở nước ta và nhiêu nước trên thế giới [1].

Trong các loại sỏi tiết niệu thì sỏi thận san hô là nguy hiểm nhất và khó điều trị nhất, do đặc điểm về hình thái, sinh bệnh học và những biển chứng. Sỏi thận được gọi là sỏi thận san hô khi sỏi bể thận có nhánh vào trong các đài thận. Sỏi thận san hô chiếm $25,4 \%$ sỏi thận, có thể gây ra các biến chứng như viêm nhiễm, suy giảm hoặc mất chức năng thận.

Năm 2016 tại bệnh viện Đa khoa tỉnh Hải Dương triển khai phương pháp tán sỏi thân qua da bằng đường hầm nhỏ dưới hướng dấn của siêu âm, kích cỡ ống nong và Amplatz là $18 \mathrm{fr}$ đã mang lại kết quả nhất định. Tuy nhiên chưa có nghiên cứu nào về kết quả điều trị sỏi thận san hô bằng phương pháp tán sỏi thận qua da đường hầm nhỏ, qua đó chúng tôi thực hiện đề tài: "Đánh giá kết quả điều trị sỏi thận san hô bằng tán sỏi qua da đường hầm nhỏ tại Bệnh viện Đa khoa Tỉnh Hải Dương năm 2020". 